\title{
Overview of the Main Anti-SARS-CoV-2 Vaccines: Mechanism of Action, Efficacy and Safety
}

\author{
Maria Teresa Mascellino (D) \\ Federica Di Timoteo \\ Massimiliano De Angelis \\ Alessandra Oliva $\mathbb{D}$
}

Department of Public Health and Infectious Diseases, Sapienza University, Rome, Lazio, Italy
Correspondence: Maria Teresa Mascellino Department of Public Health and Infectious Diseases, Sapienza University, Piazzale Aldo Moro 5, Rome, 00185, Italy Tel +3906 49970880

Fax +3906 49972628

Email mariateresa.mascellino@uniromal.it
Abstract: This review takes into consideration the principal vaccines developed against the SARS-CoV-2 in this unprecedented period of Covid-19 pandemic. We evaluated the mechanism of action of each vaccine as well as the efficacy, the safety and the storage temperature. In addition, the problem of the dose units, the vaccinal strategy, the activity of alternative compounds such as the monoclonal antibodies and especially the issue of the virus variants were also described in detail. Four vaccines are currently used in Italy: Pfizer-BioNTech mRNA BNT162b2 (Comirnaty) (USA), Moderna mRNA 1273 (USA), Astra-Zeneca ChAdOx1-S (recombinant) viral vector adenovirus belonging to Oxford (UK) and Pomezia (Italy), Janssen (two recombinant viral vector adenoviruses) belonging to Johnson \& Johnson (USA). The efficacy of Pfizer and Moderna for preventing disease or severe disease results $95-87.5 \%$ and $94.5-100 \%$, respectively. The efficacy of Astra-Zeneca and Janssen is about $70 \%$ and $65 \%$, respectively; in the case of Janssen, it depends on the geographical area ranging from $72 \%$ to $57 \%$. The problem of the administrated doses (one dose, two doses from the same vaccine or from different vaccines, half dose) is also discussed. The vaccination strategy based on the age group remains the simplest, most transparent and fair criterion. This strategy is also based on accelerating the administration of the vaccines, so that as many subjects as possible can be vaccinated quickly for achieving the "herd immunity". The monoclonal antibodies appeared to be a valid solution for the treatment of Covid-19 disease. Two antibodies (bamlanivimab and etesevimab) have just been approved by the FDA. They could also be used for the infection by virus variants which represent a big problem due to their higher transmissibility and virulence and to their lower response to the vaccines.

Keywords: Covid-19 vaccines, vaccinal strategy, dose units, monoclonal antibodies, virus variants, vaccinal platforms

\section{Introduction}

Covid-19 is a pneumonia-like disease identified first in Wuhan, China. The disease is caused by a new coronavirus, named SARS-CoV-2, similar to the severe acute respiratory syndrome (SARS) virus. SARS-CoV-2 is genetically close to the SARS$\mathrm{CoV}$ virus that emerged in 2002. Like SARS-CoV and many other coronaviruses, SARS-CoV-2 utilizes its surface spike glycoprotein to enter host cells. Each unit of the spike trimer contains an S1 and S2 subunit, with the N-terminal S1 subunit binding to the cellular angiotensin-converting enzyme 2 (ACE2) receptor through an internal receptor-binding domain (RBD). ${ }^{1}$ The novel coronavirus SARS-CoV-2 has emerged as a severe threat against public health. This virus is highly contagious and the resulting disease has led to an ongoing pandemic.

SARS-CoV-2 affects mainly the respiratory system with most severe cases presenting primarily an acute respiratory distress syndrome. ${ }^{2}$ 
Challenges in vaccine development, protective immune monitoring, and toxicity are common to the infectious disease research field. These challenges involve mainly the preparation of vaccines or novel and efficacious therapies to induce an early protective response in individuals ${ }^{3}$ During the last century, vaccines proved their efficacy to eradicate once widespread life-threatening and debilitating diseases such as smallpox and polio. The anti-CoV-2 vaccines were developed in a much shorter time than previous vaccines: past vaccines took approximately eight to ten years before being used in humans, whereas the antiSARS-CoV-2 vaccines were ready in eight to ten months.

The reason for this time difference is simple: first of all, pharmaceutical companies such as Pfizer, Moderna, and AstraZeneca invested enormous resources to achieve their goal and thereby combat this pandemic and stop the millions of deaths it has caused. Indeed, research funds are usually enough for one candidate at a time to be developed and experimented on; however, during the current situation many approaches were tested simultaneously. As a result, many preclinical candidates for the anti-Covid-19 vaccine were developed, driven by the urgency of the pandemic and the support afforded by numerous funding sources (a situation that has not existed for other vaccines). ${ }^{4}$

The most common vaccine development approach was based on the spike protein of the virus as an antigen because it is the only surface protein on the microorganism and it is readily accessible by antibodies and immunological cells in the body. ${ }^{5}$ The spike protein seemed to be the best bet to get an effective vaccine ready fast.

Another hurdle during vaccine development is the gap between research in animal models (such as mice) and its translation to human research in a clinical context. In vivo systems incorporating human cells and tissues in a physiological setting may help to close this gap. For example, humanized mice with engrafted human cells provide suitable tools to study human-specific pathogens. ${ }^{6}$

Our aim with this review was to evaluate the most common anti-Covid 19 vaccines, examining their mechanisms of action and their relative efficacy and safety as well as issues related to the vaccination strategy, the correct use of the vaccinal doses, the use of monoclonal antibodies, and the emergence of virus variants.

\section{Steps for the Covid-19 Vaccines Preparation \\ Pre-Clinical Trial}

- Vaccination to animals (animal testing little mouse)

- Monitoring the side-effects (SE)

- Efficacy (to prevent severe disease or prevent infection $\rightarrow$ asymptomatic patients)

- Virus analysis (to prevent disease)

\section{Phase I}

- Vaccine to healthy humans (small sample size $<100$ )

- Evaluation of SE

- Dosage (upper limit with more risk of SE and lower limit with a decrease of antibody response)

\section{Phase II}

- Vaccine to humans (moderate sample size 100-1000)

- Humans (match for demographic characteristic of population: race, age, sex, gender, economics)

- Evaluation of SE

- Dosage basically effective

\section{Phase III}

- Vaccine to humans (large sample size 1000-10,000)

- Humans (match for other demographic characteristics of population: blacks, whites, country, nationality, underlying diseases, comorbidities)

- Efficacy: prevention of disease (monitoring of symptoms) or prevention of infection (RT-PCR positive in order to confirm the diagnosis).

All in all, vaccine development research addresses both safety concerning the detection of side-effects and efficacy concerning the prevention of infection (AstraZeneca) or the prevention of disease or severe disease (Pfizer and Moderna).

After conclusion of an experimental phase for vaccine preparation, relevant data are transmitted for approval to the FDA (Food and Drug Administration), the EMA (European Medicine Agency), the MHRA (Medicine and Healthcare Regulatory Agency), or in Italy to the AIFA (Italian Medicines Agency). The CMA (Conditional Marketing Authorization) may give a provisory and early authorization (Emergency Use Authorization EUA) in cases of emergency or urgency.

The pharmaceutical approval process authorities apply special measures. Pharmacovigilance refers to the science 
and activities related to adverse effect detection, assessment, understanding, and prevention or to any other medicine-related problem. During the pharmaceutical approval process the EMA coordinates the European Union (EU) pharmacovigilance system and operates services and processes within the EU. The EMA's Pharmacovigilance Risk Assessment Committee (PRAC) is responsible for assessing and monitoring the safety of human medicines. EMA supports the PRAC by providing data from clinical practice in electronic health records or prescription databases.

\section{Vaccination Platforms}

The vaccination platforms for preparing the different types of vaccines are the following: ${ }^{7}$

1. mRNA vaccines developed by Pfizer-BioNTech and Moderna. RNA and DNA vaccines are a cuttingedge approach that uses genetically engineered RNA or DNA to generate a protein that itself safely prompts an immune response.

2. Viral vector (adenovirus) vaccines developed by Astra-Zeneca, Johnson \& Johnson, Reithera and Sputnik. Viral vector vaccines use a virus that has been genetically engineered so that it cannot cause disease, but produces coronavirus proteins to safely generate an immune response.

3. Inactivated virus vaccines developed by Sinovac. Inactivated or weakened virus vaccines use a form of the virus that has been inactivated or weakened so it does not cause disease, but still generates an immune response.

4. Protein subunits vaccines developed by Novavax. Protein-based vaccines use harmless fragments of proteins or protein shells that mimic the Covid-19 to safely generate an immune response.

\section{Overview of the Most Common Anti-SARS-CoV-2 Vaccines Pfizer-BioNTech (Comirnaty) BNT $162 \mathrm{~b} 2$ and Moderna (1273)}

This method utilizes lipid nanoparticles (LNPs) with a formulated mRNA vaccine. This work was fast-tracked at an unprecedented pace, even though mRNA-based vaccines have never been licensed before. ${ }^{8}$ RNA vaccines belong to a cutting-edge approach that uses genetically engineered RNA to generate a protein that safely prompts an immune response. ${ }^{9}$
mRNA-based vaccines have the greatest potential for rapid development because of their synthetic nature that circumvents the need for cell culture or fermentation of viruses. Due to their high potency, rapid development and low cost for manufacturing, mRNA vaccines have emerged as a promising alternative vaccination development strategy for various infectious diseases and cancers. ${ }^{8}$.

\section{Mechanism of Action}

The SARS-CoV-2 contains 25-28 proteins but the researchers just isolated the mRNA from the spike protein which shows 3 copies of the same protein, then only one mRNA is produced. $^{1,2}$. Several strategies have been proposed to solve the common drawbacks of mRNA-based vaccines, which include the mRNA instability with respect to DNA. In fact the mRNA lasts up to two days in our body, it is easy to degrade and requires high cold chain. The storage temperature of Pfizer-BioNTech Covid-19 vaccine was $-94^{\circ}$ Fahrenheit corresponding to $-70^{\circ}$ Celsius. Vaccine storage in this case is a problem for low and medium countries income (LMCI). Nevertheless, in these vaccines, no adjuvants or preservatives are used because the vaccine is stimulated by itself. Moreover, the mRNA is included in a lipid particle which preserves its integrity and allows it not to get confused with other RNA molecules.

From the SARS- CoV-2 virus, the mRNA (able to translate and codify for the superficial spike proteins of the virus involved in the human pathogenicity) by working from the way backwards of s-proteins, is isolated and included in a lipid nanoparticle. ${ }^{10}$ This nanoparticle is injected intramuscularly into the human body and once attached to the host cells, inserts its mRNA into the cytoplasm (not in the nucleus) in such a way as to reach the ribosomes and use them for synthesizing the viral spike proteins. This process is called translation. ${ }^{9}$ Proteins then achieve the cellular membrane and evolve in two types: the MHC-2 (antigen presenting cells) and the MHC-1 related to another antigen which is present in all the nucleated cells of our body. The MHC-2 complex is only found in particular kind of cells: B-cells, macrophages and dendritic cells. These are activated by the s-protein and attract the cells of the immune system. In particular, the T-helper (Th) cells which have a particular type of membrane protein (TCR) that binds to the viral s-protein. Other proteins called CD4 produced by the Th cells interact with the complex MHC-2. The strongly activated Th cells begin to produce cytokines such as IL-2, IL-4 and IL5. ${ }^{11}$ These interleukins cause the B-cells of our body to differentiate into plasma-cells that begin to produce a huge amount of antibodies against the viral spike proteins, able to 
neutralize or destroy the virus. Meanwhile, the interleukins also stimulate $\mathrm{Th}$ cells to proliferate the memory $\mathrm{T}$ cells. Another group of cells called T-cytotoxic cells (Tcx cells) interact with the MHC-1 protein on the cell membranes through their TCR and produce CD8 proteins. These proteins are very dangerous because may allow the Tcx cells to generate unsafe molecules which lead the cells to death if infected with the virus in the future but not the cells which are currently processing the vaccine. ${ }^{12}$ Conversely, these Tcx cells are also able to produce substances that amplify the aforementioned immune response (Figure 1).

The response to the vaccines is strong but the problem is that so far we do not know how much this immunity lasts and how long the antibodies are effective against the virus. The ideas are sometimes contrasting. This immunity should last from six to nine months. ${ }^{13,14}$

\section{Safety}

The vaccines safety concerns the detection of side-effects after the administration of the vaccine either after the first dose or after the second one. The first and second dose are administered 21 days apart then after 7 days from the last dose any possible symptom is registered.

It is reported that for both vaccines only mild or minimum side-effects are present. A small pinched pain at the injection site, a little bit of redness, fatigue, headache, muscle and joint pain and fever especially after the second dose can be noted. However, other serious

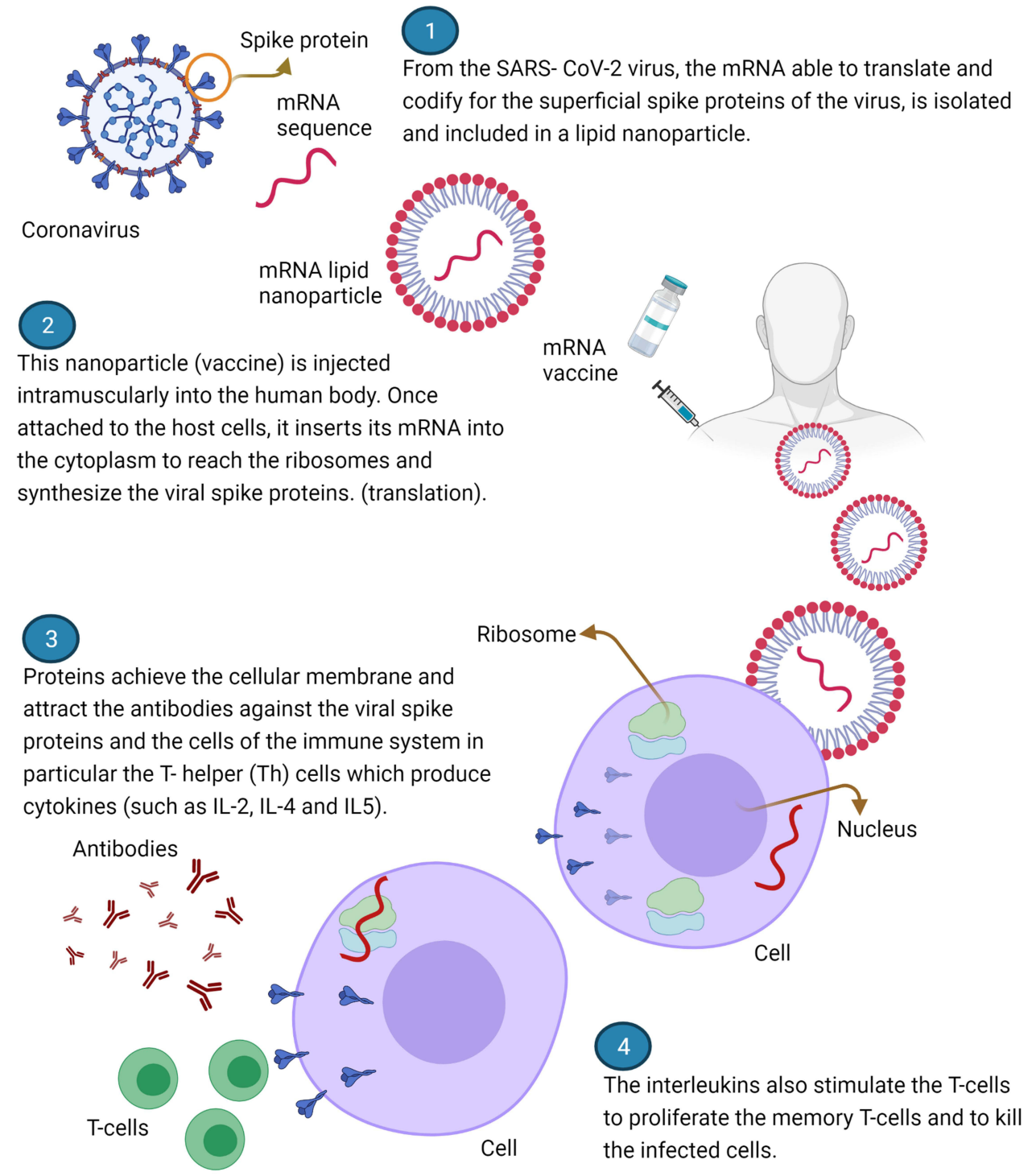

Figure I Scheme of mechanism of action of vaccines Pfizer-BioNTech and Moderna. Created with BioRender.com. 
side effects such as the syndrome of Guillain-Barre and anaphylactic and allergic reactions even though very rare, have been reported in literature for the vaccine Pfizer. ${ }^{15,16}$ From December 10 to 23, 2020, twenty-one people out of 1.893.360 undergone the first dose of Pfizer-BioNTech Covid-19 vaccine, developed serious allergic reactions including anaphylaxis, corresponding to an estimated rate of 11.1 cases per million doses administered. ${ }^{15,16}$ However, no death from anaphylaxis is reported.

Rare cases of facial paralysis (Bell's-Palsy) were reported in patients with Covid-19. However, this incidence did not result higher after vaccination (Table 1).

\section{Efficacy}

Efficacy objectives include the reduction of the risk of viral disease or the elimination of the progression to severe disease. In the evaluation of vaccine efficacy, both the risk of becoming ill and of becoming severely ill after acquiring the infection are compared between individuals taking the vaccine and those taking a placebo. ${ }^{17}$

\section{Efficacy of Pfizer-BionTech Vaccine}

Methods. Participants $(\mathrm{n}=43.000)$ were subdivided into placebo (injected with saline solution twice) or vaccine (injected with the two vaccine doses) groups. The first group reported symptoms in 162 individuals ( 9 with severe symptoms). The second group reported 8 individuals with symptoms and just 1 with severe symptoms.

Results. The efficacy against disease corresponded to $95 \%$ and the efficacy against severe disease corresponded to $87.5 \%$.

The first and the second doses were administered 21 days apart, and symptoms were registered after 7 days from the last dose.

\section{Efficacy of Moderna Vaccine}

Methods. Participants $(n=30.000)$ were subdivided into placebo (injected with saline solution twice) or vaccine (injected two vaccine doses) groups. In the placebo group, 185 individuals (30 showed severe symptoms). In the group of vaccinated individuals 11 tested positive for Covid-19 and none developed severe symptoms.

Results. In this case, the efficacy against disease was $94.5 \%$ and the efficacy against severe disease was $100 \%$.

The first and the second doses were administered 28 days apart (at present, an interval of 42 days is preferred), and symptoms were registered after 7 days from the last dose.

Table I Characteristics of the Principal Covid-19 Vaccines

\begin{tabular}{|c|c|c|c|c|}
\hline & $\begin{array}{l}\text { Pfizerl } \\
\text { BioNTtech }\end{array}$ & Moderna & Astra - Zeneca Oxford & Janssen Johnson \& Johnson \\
\hline $\begin{array}{l}\text { Mechanism } \\
\text { of action }\end{array}$ & mRNA & mRNA & $\begin{array}{l}\text { Adenovirus Viral vector (Replication deficient } \\
\text { chimpanzee adenovirus) }\end{array}$ & $\begin{array}{l}\text { Adenovirus Viral vector (Replication } \\
\text {-incompetent human Adenovirus } \\
\text { serotype } 26 \text { ) }\end{array}$ \\
\hline Antigen & $\begin{array}{l}\text { Full - length } \\
\text { spike protein }\end{array}$ & $\begin{array}{l}\text { Full - length } \\
\text { spike protein }\end{array}$ & Spike protein & Spike protein \\
\hline Doses & $\begin{array}{l}2 \text { doses } 21 \\
\text { days apart }\end{array}$ & $\begin{array}{l}2 \text { doses } 28 \text { days } \\
\text { apart }\end{array}$ & 2 doses 12 weeks apart & Only I dose \\
\hline Side effects & $\begin{array}{l}\text { Rare allergies } \\
\text { and } \\
\text { anaphylaxis }\end{array}$ & $\begin{array}{l}\text { Rare facial } \\
\text { paralysis (Bell's } \\
\text { Palsy) }\end{array}$ & $\begin{array}{l}\text { Rare thromboembolic events, rare cases of blood- } \\
\text { clots, pulmonary embolism, thrombocytopenia }\end{array}$ & $\begin{array}{l}\text { Rare cases of blood clots, } \\
\text { thrombocytopenia, Guillain-Barré } \\
\text { Syndrome }\end{array}$ \\
\hline $\begin{array}{l}\text { Overall } \\
\text { efficacy }\end{array}$ & $\begin{array}{l}95 \% \text { for } \\
\text { disease } \\
87.5 \% \text { for } \\
\text { severe } \\
\text { disease }\end{array}$ & $\begin{array}{l}94 \% \text { for disease } \\
100 \% \text { for } \\
\text { severe disease }\end{array}$ & $\begin{array}{l}70 \% \\
(64 \% \text { after I dose) } \\
\text { (70.4\% after } 2 \text { doses) }\end{array}$ & $\begin{array}{l}72 \% \text { in the USA } \\
66 \% \text { in Latin America } \\
57 \% \text { in South Africa }\end{array}$ \\
\hline $\begin{array}{l}\text { Storage } \\
\text { Temperature }\end{array}$ & $\begin{array}{l}-70{ }^{\circ} \mathrm{C} \\
2-8{ }^{\circ} \mathrm{C} \text { for } 5 \\
\text { days }\end{array}$ & $\begin{array}{l}-20^{\circ} \mathrm{C} \\
2-8{ }^{\circ} \mathrm{C} \text { for } 30 \\
\text { days }\end{array}$ & $2-7^{\circ} \mathrm{C}$ for 6 months & $2-8{ }^{\circ} \mathrm{C}$ for 3 months \\
\hline
\end{tabular}




\section{Storage Temperature and Vaccine Numbers}

The storage temperature for the Pfizer vaccine is $-94^{\circ}$ Fahrenheit $\left(-70^{\circ} \mathrm{C}\right)$ and that for the Moderna vaccine is $-4^{\circ}$ Fahrenheit $\left(-20^{\circ} \mathrm{C}\right)$.

The number of Pfizer vaccines developed in 2020 was 50 million; but 1.3 billion are expected to be developed during the course of 2021. For the Moderna vaccine, these values are 20 million and 1 billion, respectively. ${ }^{12}$

Table 1 shows characteristics of these vaccines. Data sheets are reported in the references section. ${ }^{18,19}$

\section{Astra-Zeneca Oxford}

AstraZeneca produced a viral vector vaccine using a genetically engineered virus that cannot cause disease, but that encodes coronavirus proteins to safely generate an immune response. This vaccine was initially used in the UK and has been available in Italy and Poland since the 9th of February 2021.

\section{Mechanism of Action}

The AstraZeneca vaccine uses a modified chimpanzee DNA adenovirus, which has not been exposed to human populations and does not generate an immune response to the adenovirus itself, but only to the viral protein encoded in the host DNA. ${ }^{12}$

The DNA vector encodes a protein similar to the viral s-peptide to generate an immune response against it. The DNA vector is used as a template in human cells to generate new chimpanzee adenovirus replicas and produce the viral protein that elicits an immune response. Briefly, the chimpanzee adenovirus is injected into humans and it latches to the host cells. The DNA gets released into the cytoplasm and later migrate into the cell nucleus. It does not get incorporated into the cellular DNA, but uses the host enzymes to get converted into mRNA that migrates back into the cytoplasm and interacts with host cell ribosomes (free or bound to the endoplasmic reticulum), resulting into translated proteins. The proteins get expressed on the cell membranes forming $\mathrm{MHC1}$ and $\mathrm{MHC} 2$ complexes. At this point, the mechanisms of RNA and DNA vaccines is similar and leads to the activation of T-, B-, and plasma cells and antibodies $20^{20}$ (Figure 2).

\section{Safety}

The initial studies showed a safe vaccine with some mild adverse effects including pain at the point of injection, redness, myalgias, arthralgias, and headache. However, the MHRA (Medicines and Health-Care Regulatory Agency) reported 13 patients with allergic reactions (all individuals made a full recovery) and 6 patients with facial paralysis (Bell's-Palsy); these adverse effects were not proven to be caused by the vaccine. Most of 143 individuals reported to have died shortly after vaccination were elderly patients with underlying health conditions and, consequently, these deaths did not suggest a direct vaccine cause. However, the evaluation of the vaccines' adverse effects is ongoing. Fears have circulated about potential sideeffects of the AstraZeneca vaccine such as thromboembolic events or rare blood clots associated with thrombocytopenia with or without bleeding (including cerebral venous sinus thrombosis [CVST] or pulmonary embolism). ${ }^{21}$ These collateral effects prompted the EMA to withdraw the vaccine from the market on March 15th 2021, but it was approved back again after 3 days stating that the benefits of the vaccine outweigh its risks. In addition, the EMA underlined the lack of evidence for problems with specific vaccine batches. Moreover, the agency noted that among 20 million people who had received the vaccine in Europe, only 7 individuals presented disseminated intravascular coagulation (DIC) and 18 presented CVST (with 9 deaths). ${ }^{21,22}$ Most of these manifestations occurred in women under 55 years. As a result of this, AstraZeneca has been banned for people under 60 years in Germany and in other European countries. A causal link for these problems with the vaccine has not been proven; however, it was established that the phenomenon deserves further analysis.

\section{Efficacy}

For this vaccine, the efficacy was calculated as the capacity to prevent infection, not the disease. The infection implies the replication of the SARS-CoV-2 virus in the body and it may or may not cause symptoms (disease). Viral shedding (and transmission to other people) may occur even if a disease does not develop. Thus, asymptomatic individuals were identified, and the transmissibility of the virus to other people was evaluated. The transmission of the infection was detected by RTPCR on the examined samples.

The first and the second doses were administered 28 days apart (12-week intervals are under study). After 14 days, the presence of infections was detected by PCR. Exploratory analyses showed a higher vaccine efficacy with longer prime-boost intervals, and also that a single 


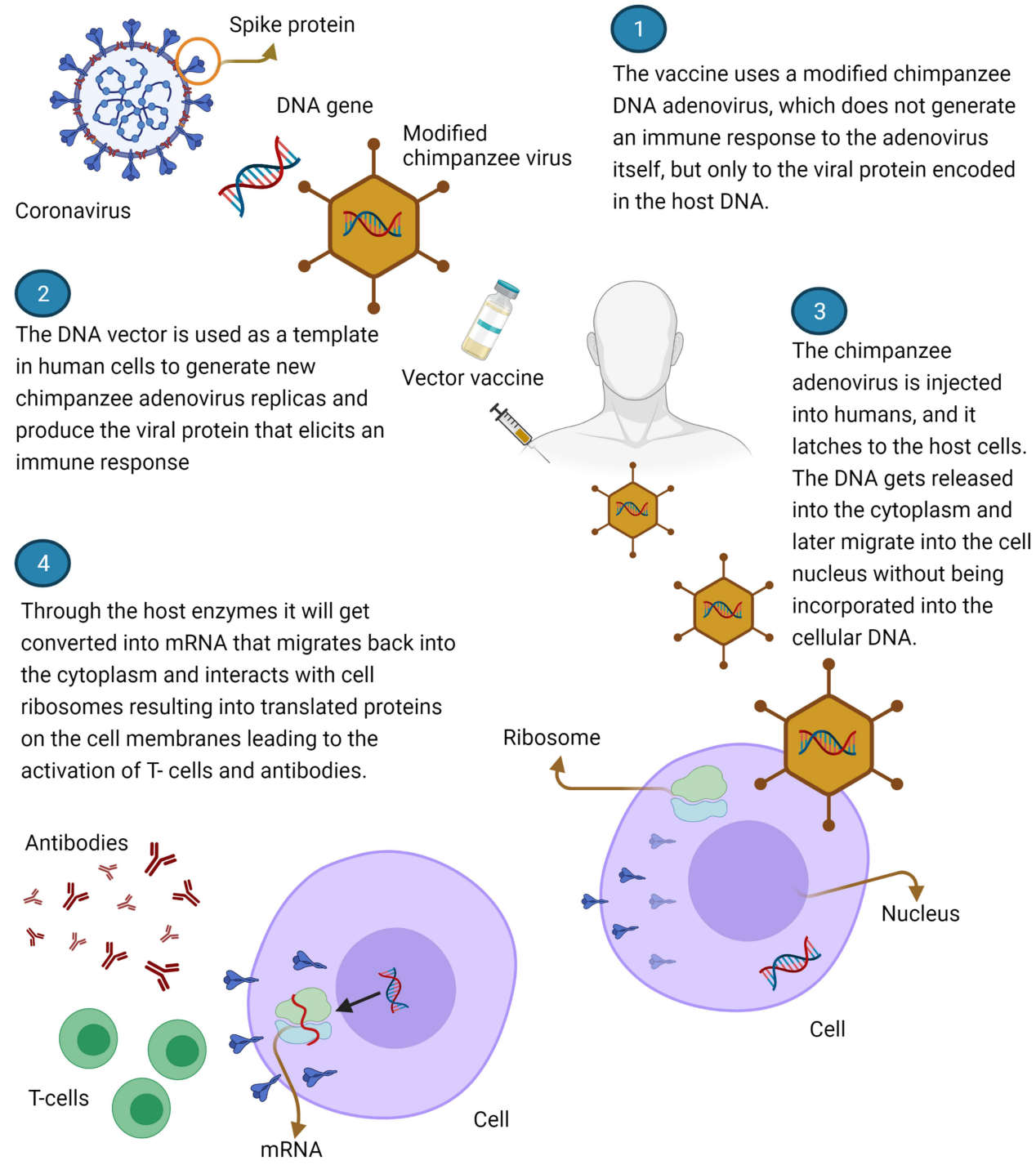

Figure 2 Scheme of mechanism of action of vaccine Astra-Zeneca. Created with BioRender.com.

vaccine dose is efficacious during the first 90 days, providing further evidence for current policy. ${ }^{23}$

On February 18 2021, the AIFA approved the use of the vaccine for people 65 years and older and mainly in countries with circulating viral variants. ${ }^{24}$

\section{Methods}

Two studies were conducted in parallel in Brazil (9000 participants subdivided into placebo and vaccine groups were injected with two full doses) and in the UK (3000 participants subdivided into placebo and vaccine groups injected with half and full doses, the second dose after 28 days).

\section{Results}

In the Brazilian study, the efficacy of the vaccine was approximately $62 \%$, whereas in the UK study, it reached $90 \%$. Thus, the mean efficacy value with data of 12.000 participants from both studies was $70 \%$ with 131 positive cases and zero with severe symptoms. The WHO (World Health Organization) reported a vaccine efficacy for the AstraZeneca/Oxford vaccine, called ChAdOx1-S (recombinant), at 63.09\%, and stated that the vaccine is suitable for low- and middle-income countries due to its simple storage requirements.

\section{Storage Temperature and Vaccines Number}

The storage for this vaccine is easy because it can be kept at refrigerator temperature $\left(2^{\circ}-7^{\circ} \mathrm{C}\right)$. The number of vaccines expected during 2021 ranges from 3 to 4.5 billion.

AstraZeneca vaccine changed the name of the vaccine to Vaxzevria with the approval of the EMA on the 25th of March 2021, following a request from the Anglo-Swedish pharmaceutical group. 
Table 1 shows the vaccine characteristics; and the data sheets are reported in the references section. ${ }^{25}$

\section{Janssen (Johnson \& Johnson)}

An investigational Covid-19 vaccine developed by Janssen Pharmaceuticals (Johnson \& Johnson, USA) appears to be safe and effective at preventing moderate and severe Covid19 in adults. The vaccine, called Ad.26.COV2.S or JNJ78436725 needs a single injection and can be stored in a refrigerator for months (it does not require extreme coldstorage environments because it is not mRNA-based). This vaccine acts through an adenovirus engineered in a laboratory. ${ }^{26}$ On March 1st 2021, the US FDA issued an emergency use authorization (EUA) for this vaccine to be distributed in the United States in individuals 18 years and older for the prevention of Covid-19. Afterwards, on March 12th of the same year, the EMA and the AIFA authorized the vaccine in Italy based on its efficacy to prevent severe forms of the disease including hospitalizations and deaths, which reaches $77 \%$ after 14 days of the administration and $85 \%$ after 28 days. Currently available data showed a similar efficacy in individuals over 65 years. This vaccine was approved in Italy in April. It has been used for some time and was then withdrawn due to important side effects but subsequently it was put back again on the market.

\section{Mechanism of Action}

This vaccine employs a harmless cold virus (adenovirus $26 \mathrm{CoV} 2)$ to deliver a gene that carries the blueprint for the spiky protein found on the surface of the coronavirus. The mechanism of action of the vaccine is similar to that of the AstraZeneca vaccine. An adenovirus vector manipulated in the laboratory carries genetic information for the spike-protein in the viral DNA that can generate a specific mRNA. The DNA portions of this adenovirus that would allow it to replicate were deleted from the vector, and consequently, the vector cannot get replicated in human cells. The vaccine is injected into the individuals, and the vector latches onto human cells, where the DNA carrying the information for the SARS-CoV-2 spike protein is transferred into the nucleus without being incorporated into the host cell DNA. The strand of the viral DNA that would normally tell the cell to make more adenovirus particles, gets translated into mRNA that gets transported out into the cytoplasm, where the cell machinery instead of making adenovirus particles produces spike protein. At this point, the viral spike proteins at the surface of the cells induce production of T-cells (CD4 and CD8), cytotoxic cells, plasma cells, ILs, and B-cells that constitute the three primary immune responses (antibodies, Killer CD8 T-cells and helper CD4T-cells) to block the infection. ${ }^{27,28}$ T-cells are crucial for destroying infected human cells, and the antibodies are effective to protect uninfected cells when free viral particles are circulating out of cells (antibodies can easily latch onto spike proteins on the viral surface).

\section{Safety}

Weak side-effects were found during the administration of this vaccine including pain, redness, and swelling at the injection site. However, on April 13 2021, the CDC and the FDA recommended a "pause" in the use of the Johnson \& Johnson Covid-19 vaccine due to the report of six cases of a rare and severe type of blood clot in individuals after receiving the vaccine in the US. This led to a stop of the use of this vaccine in Italy, although it had just been approved for emergency use.

\section{Efficacy}

The investigational Janssen Pharmaceuticals vaccine requires a single shot, which constitutes a great advantage because the vaccine supply needs to be half of that of other vaccines and because individuals need to be contacted only once. These advantages could simplify the vaccine distribution and expand access to shots domestically and world-wide. This vaccine could accelerate the increasingly urgent race to broaden immunity against the virus variants, which challenge the current generation of vaccines. Presently, it is used in Russia, but many other countries worldwide are requesting permission to manufacture it.

\section{Methods}

The participants for this ensemble trial (45\% women and 55\% men) were 43.783 (44\% from the USA, 41\% from Central/ South America, and 15\% from South Africa). Among these, 468 individuals tested positive for symptomatic Covid-19.

\section{Results}

The vaccine trial was primarily designed to measure how well the vaccine prevented illness. It was overall $66 \%$ effective at preventing moderate and severe disease 4 weeks after the shot among all volunteers, including those infected with an emerging viral variant, a result that covers a wide range of variation depending on geography: $72 \%$ effective in the United States, $66 \%$ in Latin America, and $57 \%$ in South Africa, where concerning 
variants have taken root. $^{27}$ Overall, 16 deaths were reported in the placebo group, and 3 deaths in the vaccine group (but not due to Covid-19).

Company executives emphasized that the vaccine was $85 \%$ effective at preventing severe illness and that no cases of Covid-related hospitalizations or deaths had been found in people who had received the vaccine - an outcome that most people would find satisfactory. This vaccine induced production of antibodies within 49 days after the single shot, and during these 49 days no hospitalizations or deaths were noted (even in South Africa, where many virus variants were circulating). This is an encouraging result. ${ }^{27,29}$

\section{Storage Temperature and Vaccines Number}

This vaccine, also called JNJ-78436725, can be stored in a refrigerator for months because it does not use an mRNA vector, which would degrade quickly at these temperatures. The managers of the American company aim to produce one billion doses of their vaccine during 2021. Table 1 shows the vaccine characteristics; and the data sheets are shown in the references section. ${ }^{30}$

\section{Sputnik V (Russian Vaccine)}

This vaccine is being used in Russia for emergencies. On August 11th 2020, the Russian Health Ministry registered the Sputnik V, which became the first vaccine registered in the world against Covid-19. Other nations are trying to manufacture it. The first European nation to approve the vaccine was Hungary, where the National Institute of Pharmacy and Nutrition authorized it for emergency use. The vaccine has been approved in Russia, Belarus, Serbia, Argentina, Bolivia, Algeria, Venezuela, Paraguay, Turkmenistan, UAE, Iran, Guinea, Tunisia, Armenia, and in the Palestinian territories. To date, more than 2 million people worldwide have received the Sputnik V vaccine. The EMA and the AIFA are evaluating the possibility of authorizing this vaccine in Italy for emergencies. Sputnik V remains under a review process.

This vaccine is based on two different human adenoviral vectors (Ad 26 and Ad 5) which could stimulate a stronger and longer immune response than other vaccines using the same vector in two doses. Moreover, the vaccine cost is twice cheaper than the cost of other vaccines with the same efficacy rate according to the CEO of the Russian Direct Investment Fund, Kirill Dmitriev.

\section{Mechanism of Action}

The approach is similar to those of the AstraZeneca and Johnson \& Johnson vaccines. In fact, the adenovirus with an engineered DNA fragment, infects the cells, which then follow genetic instructions to construct a replica of the coronavirus spike able to generate the production of antibodies and of the T-cells that protect individuals from future infections. The viral vector (adenovirus) cannot replicate in human cells.

\section{Safety}

The Sputnik does not produce serious side-effects. It is recognized as a safe vaccine with neglectable effects similar to those of the flu vaccination.

\section{Efficacy}

The Sputnik V vaccine is a two-dose adenoviral vector vaccine using two different adenoviruses for each dose (the first and second doses are administered 21 days apart). The vaccine was quickly administered to people, even before the crucial Phase 3 trials were conducted. The preliminary findings were published in The Lancet on February 16th 2021 and are based on data gathered from 19.866 participants, of which around three-quarters (14.964) received two doses of the vaccine and a quarter (4902) was given a placebo. ${ }^{31 .}$ Sixteen cases of symptomatic Covid-19 were confirmed in the vaccine group 21 days after the first vaccine dose, and 62 cases were found in the placebo group for an efficacy of $91.6 \%$ (Table 2).

The use of a different adenovirus vector for the booster vaccination may help create a more powerful immune response. $^{32}$

The Spallanzani Hospital in Rome (Italy) agrees to use this vaccine in Italy because it has proven safe and effective. Indeed, the results have shown a clinical efficacy $>90 \%$ for symptomatic disease and $100 \%$ for severe disease. On February 17 2021, the National Institute for Infectious Diseases in Rome stated that the Sputnik V vaccine may play a crucial role during the vaccination programs against SARS-CoV-2. One region in Italy belonging to foreign land, San Marino, has already started applying this vaccine to the general population. The cost is of $\$ 10$ per dose, according to Russian Direct Investment Fund, which sponsored the vaccine production and is responsible for selling it globally.

\section{Storage Temperature and Vaccines Number}

One advantage of the adenoviral vaccines is that they do not need to be stored and transported under extremely cold temperatures. Sputnik V needs to be refrigerated in dry 
Table 2 Characteristics of Vaccines Developed in Other Countries

\begin{tabular}{|c|c|c|c|c|}
\hline & NOVAVAX (USA) & $\begin{array}{l}\text { CUREVAC } \\
\text { (Germany) }\end{array}$ & $\begin{array}{l}\text { SINOVAC OR CORONAVAX } \\
\text { (China) }\end{array}$ & SPUTNIK (Russia) \\
\hline $\begin{array}{l}\text { Mechanism } \\
\text { of action }\end{array}$ & Protein Subunit & $\begin{array}{l}\text { Modified } \\
\text { m-RNA }\end{array}$ & Inactivated virus & $\begin{array}{l}\text { Two adenovirus (recombinant-ad } 26 \\
\text { and recombinant-ad 5) viral vector }\end{array}$ \\
\hline Antigen & $\begin{array}{l}\text { Recombinant full - } \\
\text { length, } \\
\text { prefusion } 5 \text { protein }\end{array}$ & $\begin{array}{l}\text { Prefusion stabilized } \\
\text { full - length } 5 \text { protein }\end{array}$ & $\begin{array}{l}\text { Inactivated strain of SARS-CoV-2 } \\
\text { created from vero -cells }\end{array}$ & Gene spike glycoprotein \\
\hline Side effects & $\begin{array}{l}\text { Muscle pain, just one } \\
\text { case of myocarditis }\end{array}$ & $\begin{array}{l}\text { Unknown, Trials in } \\
\text { progress }\end{array}$ & No serious side effects & No serious side effect \\
\hline Doses & $\begin{array}{l}\text { Two doses 4-12 } \\
\text { weeks apart }\end{array}$ & $\begin{array}{l}\text { Two doses } 28 \text { days } \\
\text { apart }\end{array}$ & Two doses 14 days apart & Two doses 21 days apart \\
\hline Efficacy & $\begin{array}{l}89.7 \% \text { in the UK } \\
60 \% \text { in South Africa }\end{array}$ & $47 \%$ & $\begin{array}{l}65 \% \text { for prevention of Covid } 19 \text {, } \\
86-90 \% \text { for prevention of } \\
\text { hospitalization, ICU admission and } \\
\text { death }\end{array}$ & $91.6 \%$ \\
\hline $\begin{array}{l}\text { Storage } \\
\text { temperature }\end{array}$ & $\begin{array}{l}2-8^{\circ} \text { C.for six } \\
\text { months }\end{array}$ & $\begin{array}{l}2-8{ }^{\circ} \mathrm{C} \text { for three } \\
\text { months }\end{array}$ & $2-8^{\circ} \mathrm{C}$ & $\begin{array}{l}-18^{\circ} \mathrm{C} \text { (liquid form) } \\
-2-8^{\circ} \mathrm{C} \text { (dry form) }\end{array}$ \\
\hline
\end{tabular}

form and requires a temperature of $-18^{\circ} \mathrm{C}$ in liquid form (Table 2). The expected vaccine production numbers remain unknown.

\section{New Vaccines Still in Progress}

The effort by all nations to find an effective vaccine is crucial to increase the global supply and achieve a strong and efficacious vaccination campaign.

In addition to the vaccines mentioned above, many others are still under evaluation in Phase 2 or 3 trials. The principals of those vaccines will be listed briefly in the following paragraph.

\section{Novavax (NVX)}

NVX-CoV2373 from the USA uses protein subunits of the virus. These protein-based vaccines use harmless protein fragments or protein shells that mimic the Covid-19 virus spike protein to safely generate an immune response. ${ }^{33}$ Approval of the vaccine is underway by the EMA. The decision of the CHMP (Committee for Medicinal Products for Human Use) to initiate the review process is based on preliminary laboratory and clinical data in adults that suggest production of substantial humoral and cellular immunity against SARS -CoV-2. The rolling review is a tool used by regulatory authorities to accelerate the evaluation of potentially promising experimental drugs and vaccines during a health emergency.
This vaccine contains an adjuvant (saponin), which strengthens the human immune response. ${ }^{33}$ Novavax was found to be highly effective $-89.7 \%$ - in a trial where the B.1.1.7 variant first identified in the United Kingdom was greatly prevalent (source Novavax, January 28th 2021). However, its efficacy dropped to $60 \%$ in a smaller and less definitive South African trial, where the vast majority of infections belonged to the B. 1.351 variant that is spreading there (Table 2). ${ }^{34}$

\section{Reithera}

ReiThera from Italy (Castel Romano and Spallanzani Hospital in Rome) utilizes a genetically engineered primate viral vector that cannot cause disease, but is still able to produce coronavirus proteins to safely generate an immune response. Antibodies were found in more than $94 \%$ of vaccinated individuals after a single dose. ${ }^{35}$

The first results of these experiments were presented by researchers at the Spallanzani Hospital in Rome (Italy). The trial is still in progress and should be ready next summer. This vaccine is stable at a temperature from $2^{\circ}$ to $8^{\circ} \mathrm{C}$.

\section{Sinovac or Coronovax}

Sinovac or Coronovax, from China and Brazil, uses inactive virus as antigen. Inactivated or weakened virus vaccines are based on a form of the virus that has been 
inactivated or weakened so that it does not cause disease, but is still able to generate an immune response. This vaccine has been used in other countries such as Indonesia, Turkey, and Singapore. The efficacy against mild or moderate disease forms detected by some researchers during preliminary studies was found to be $78 \%$ (BBC news). ${ }^{36}$ Its current effectiveness is approximately $65.9 \%$ for the prevention of Covid- $19,87.5 \%$ for the prevention of hospitalizations, $90.3 \%$ for the prevention of ICU admissions, and $86.3 \%$ for the prevention of Covid-19-related deaths (Table 2). ${ }^{37}$

\section{Curevac}

Curevac from Germany is a vaccine based on a modified mRNA like the Pfizer and Moderna vaccines. The EMA has started the rolling review process for this vaccine to evaluate the usual standards of efficacy, safety, and pharmaceutical quality. Its current efficacy is low (47\%), below the minimum threshold of $50 \%$ as established by the WHO. The storage temperature is $2-8^{\circ} \mathrm{C}$ (Table 2).

\section{VXA-CoV2}

VXA-CoV2-1 from Vaxart (San Francisco, California) is an investigational vaccine to be administered orally by tablet rather than by injection. It is generally well-tolerated and has induced an immune response against SARS-CoV-2 antigens in a Phase I study. IgA ASC (antibody secreting cells) were the most important immune parameter to predict protection from the oral immunization. VXA-CoV2-1 could have a broader activity against existing and future coronavirus strains considering the emergence of variants with low responses to first-generation vaccines. This vaccine may be considered as belonging to a next generation. The VXA-CoV2-1 candidate contains two different SARS-CoV-2 proteins, Spike (S) and Nucleoprotein $(\mathrm{N})$, a design which the company hopes will protect against both prevalent and emerging strains; all other Covid-19 vaccines include just the S protein. Next-generation vaccines will be proven to protect against a broader spectrum of viral variants by being able to cover spike mutations with a greater and more potent T cellular response. ${ }^{38}$ Preliminary data have shown that the vaccine tablet is well-tolerated, and with only mild adverse events. The storage temperature is room temperature $\left(25^{\circ} \mathrm{C}\right)$.

\section{E-Vax}

E-Vax is an Italian vaccine whose trial begun in March 2 of 2021 with the first volunteer, a 21-year-old young man, who was given a dose of $0.5 \mathrm{mg}$ of the vaccine developed by the Roman Society Takis and Rottapharm Biotech from Monza (Italy). This vaccine uses a DNA platform, a cutting-edge approach that uses genetically engineered DNA to generate a protein that can safely prompt an immune response. ${ }^{39}$ The DNA is injected through an electroporator to shock the cell membrane and allow fragments of DNA to enter the cells. The importance of this vaccine arises from the possibility of modifying it to adapt it to the emergence of virus variants that are not completely susceptible to current vaccines. Thus, this modifiable vaccine presents an important opportunity. Furthermore, it is stable at room temperature and can be administered many times in case that the anti-Covid-19 vaccinations need to be repeated annually. High doses up to $200 \mathrm{mg}$ will be evaluated considering the possibility of being able to avoid a second dose.

\section{Covid Vaccines for Kids and Adolescents}

Covid vaccines for kids and adolescents are in the works (https://www.bbc.com/news/health-57239066). Pfizer and Moderna have enrolled children older than 12 years in clinical trials and hope to have results by the summer. On March 31 of 2021 Pfizer/BioNTech reported that their coronavirus vaccine is highly effective in adolescents. A clinical trial found neither symptomatic infections nor serious side effects among 2260, 12 to 15 year-old vaccinated children. The placebo group had 18 Covid-19 cases.

Following the positive results in this age group, the companies are testing their vaccines in younger children. Moderna stated that its Covid vaccine is highly effective in adolescents aged 12 to 17 . No cases of Covid-19 were seen in a trial involving 3732 young volunteers who received two doses of the vaccine, compared with the four cases of Covid-19 among the controls who had placebo injections. Moderna's vaccine is currently authorized for people older than 18 years. However, the pharmaceutical agency will soon submit data to regulators globally to seek approval for use of its vaccine in teens. The Pfizer vaccine has already been approved for use in US adolescents over 16 . 
This vaccine is also being tested in children under 12, with the aim of involving babies from just six months old. ${ }^{40}$ Although teenagers rarely get seriously ill with Covid-19, they can spread the infection. Experts hope that vaccinating them against the virus will help stop the pandemic. $^{41}$

The UK has not yet approved any vaccines for younger teens or children.

Three other companies - Johnson \& Johnson, Novavax, and AstraZeneca - also plan to test their vaccines in children, but their trials are further behind.

\section{Highlights on the Populations at High Risk for Adverse Events}

In order to provide a clear picture of the aforementioned vaccines, we will briefly focus on the adverse events detectable after vaccination and on the populations with high risks. Serious adverse events after Covid-19 vaccinations are rare but may occur. Severe allergic reactions, including anaphylaxis, can occur after any vaccine. ${ }^{16}$ People more prone to this drawback are those who have already shown allergic episodes throughout their life regardless of the vaccine. Thrombosis with thrombocytopenia syndrome (TTS) after a Janssen Covid-19 vaccination is rare. As of June 28, 2021, more than 12.3 million doses of the Janssen vaccine have been administered in the United States. The CDC and the FDA identified 38 confirmed reports of people who got this vaccine and later developed TTS. Women younger than 50 years should especially be aware of the rare but increased risk of this adverse event. For the AstraZeneca vaccine, thrombosis seems to be a complication of the vaccine especially in people younger than 60 years. ${ }^{21,22}$ In one Italian case, a young girl (18 years) died three days after the vaccination.

Myocarditis and pericarditis after Covid-19 vaccines are rare. As of June 28, 2021, VAERS (Vaccine Adverse Events Reporting System) has received 780 reports of myocarditis or pericarditis among people 30 years and younger who received a Covid-19 vaccine. ${ }^{34,42}$

On July 14th, US FDA includes risk of Guillain-Barré Syndrome (GBS) in Janssen COVID-19 vaccine pertaining to an observed increased risk of GBS following vaccination (source: US Food and Drug Administration https:// www.fda.gov/news-events/press-announcements/corona virus-covid-19-update-july-13-2021).
Most cases have been reported after mRNA Covid-19 vaccination (Pfizer-BioNTech or Moderna), particularly in male adolescents and young adults.

The CDC and the FDA have confirmed 518 reports of myocarditis or pericarditis through follow-ups and medical record reviews. Reports of death after Covid-19 vaccination are rare. More than 324 million doses of Covid-19 vaccines were administered in the United States from December 14, 2020, through June 28, 2021. During this time, only 5718 deaths $(0.0018 \%)$ were reported among the people who received the vaccine. ${ }^{43}$

Frail or old people, those with comorbidities, teachers, and health care personnel are at higher risk for adverse events after vaccination.

\section{Virus Variants and Vaccines}

The virus variants, widespread since September 2020, constitute a huge concern threatening vaccine efficacy. The VOC 202012/01 variant, lineage B.1.1.7 (commonly called "English variant") is defined by the presence of numerous mutations in the spike protein of the virus (deletion 69-70, deletion 144, amino acid substitutions N501Y, A570D, D614G, P681H, T716I, S982A, and D1118H) and in other regions of the viral genome. This variant was first identified in South-Eastern regions of the UK in December 2020 in conjunction with a rapid increase in the number of newly confirmed cases of SARSCoV-2 infection. ${ }^{44}$ Retrospective studies have documented the circulation of this variant starting in September 2020. ${ }^{45}$ Afterwards, the variant has rapidly spread in the UK and in other countries. Almost all the countries of the European Union including Italy, have notified the presence of cases of SARS-CoV-2 virus infection caused by the VOC variant 202012/01, lineage B. 1.1.7. ${ }^{46}$

In Italy as of March 18th, the prevalence of this virus variant has increased achieving a value of $86.7 \%$ (the previous value was 20\%) ranging between $63.3 \%$ and $100 \%$ depending on the individual regions. For the "Brazilian" P1 variant the prevalence was $4.0 \%(0 \%$ to $32.0 \%$ ), while those for the other monitored variants remain below $0.5 \%$. According to laboratory study findings published in The New England Journal of Medicine, the BNT162b2 vaccine (Pfizer/BioNTech) was able to neutralize the P.1 variant of severe acute respiratory syndrome that first appeared in Brazil as well as the variant B 1351 variant from South Africa, where it is dominant. ${ }^{47}$ However, the Pfizer BioNTech giant reported on April 1st that their Covid-19 vaccine is currently $91.3 \%$ effective at 
preventing disease (a percentage lower than the $95 \%$ efficacy reported in the first study done in November 2020 on 44.000 people). This discrepancy is surely due to the presence of variants.

Furthermore, a two-dose regimen of the ChAdOx1 nCoV-19 vaccine (AstraZeneca) did not show protection against mild to moderate coronavirus disease 2019 due to the B.1.351 variant, also known as the South African variant. The B.1.351 (N501Y.V2) lineage first identified in South Africa contains three receptor-binding domain mutations and five additional N-terminal domain mutations. ${ }^{48}$

Conversely, according to a study published in The Lancet on March 31st, the ChAdOx1 nCoV-19 (AZD1222) vaccine showed some effectiveness against the B.1.1.7 variant of SARS-CoV-2, despite a reduced neutralization activity against the B.1.1.7 variant compared with the activity against a non-B.1.1.7 variant in vitro. ${ }^{24}$ Laboratory identification of these mutations needs a multi target molecular diagnostic RT-PCR test capable of detecting multiple genes of the virus and not just the spike (S) gene, which could give negative results in the case of a variant with a deletion within the $\mathrm{S}$ gene.

Since May 31st 2021, the names for the Sars-CoV-2 variants have changed as announced by the WHO (according to the new nomenclature system) into the letters of the Greek alphabet: the English variant B.1.1.7 is now called Alpha, the South African (B.1.351) variant is called Beta, the Brazilian (P.1) variant is called Gamma, and the recently appeared variant in India (B.1.617.2) is called Delta. The WHO technical manager for Covid-19 claimed that the Greek letters will not replace the existing scientific names, but are intended to simplify public discussions and help to abolish the association of the variants with the countries where they were initially detected. The Indian variant begun to circulate only recently, but has become more aggressive, transmissible, and resistant to the current vaccines in a short time.

SARS-CoV-2 mutations may limit vaccine efficacy. ${ }^{49}$ Indeed, the mutated viruses are known to be more fit and to survive better resulting in more aggressive and transmissible phenotypes. However, antibodies and T-cells will generally still recognize these viruses because they are able to identify little bits of sequence along the viral genome (it is difficult for viruses to escape the T-cell pressure). Moreover, B-cells are also active against the variants. In fact, some memory B-cells anticipate new variants and can mutate as needed. ${ }^{50} \mathrm{~A}$ single spike protein receptor binding domain (RBD) mutation should not affect vaccine efficacy because antibodies do not bind to a single receptor domain, and several neutralizing antibodies are able to bind all around the spike protein. Both antibodies and the T-cells may still recognize mutated viruses. ${ }^{20}$ However, the matter remains controversial.

The Delta variant has increased its presence on the regional territory in Italy very fast reaching a prevalence of $2.5 \%$ in the survey of May 18 th and of $22.7 \%$ to $34.9 \%$ on July 2nd. Seventy-four percent of patients with the Delta variant are unvaccinated, a proportion that rises to $94 \%$ if we add those vaccinated with a single dose. In the UK, the spread of the delta variant, characterized by greater transmissibility, has seen an increase of $66.9 \%$ in infections during the last week. The Pfizer vaccine decreased its efficacy from $94 \%$ to $64 \%$. However, the decline in protection concerns infections and not serious forms of the disease. Furthermore, the number of hospitalizations or deaths do not seem to be affected as reported by Yaniv Erlich in an Israeli study (data not published). Two doses of Pfizer's BioNTech Covid-19 vaccine (BNT162b2) induce cross-neutralization of at least some of the circulating SARS-CoV-2 variants, according to a study published in Nature Communications. ${ }^{51}$

Dr. Scott Gottlieb, former FDA commissioner, said that the Johnson \& Johnson vaccine, which shows a vaccine efficacy of $66.9 \%, 14$ days after administration, appears to be $60 \%$ effective against the Delta variant. Indeed, the Ad26.COV2. S (Janssen vaccine) elicits neutralizing activity against Delta and other SARSCoV2.S variants of concern.

The Moderna vaccine has been shown to have an efficacy of approximately $94.1 \%$ for protecting against Covid-19 starting 14 days after the first dose, and also showing good activity against the Delta variant. ${ }^{52}$

It has been reported that in individuals that were not previously infected with SARS-CoV-2, a single dose of either Pfizer or AstraZeneca vaccines barely induced neutralizing antibodies against both variants Delta and Kappa (B.1.617.1 Kappa and B.1.617.2 Delta) through 3 months after infection or after receiving the second dose of vaccine. The experiments indicate that Pfizer and AstraZeneca vaccine-elicited antibodies are efficacious against Delta variant, but about 3-5 fold less potent than against Alpha variant. There was no major difference in the levels of antibodies elicited by Pfizer or AstraZeneca vaccines. ${ }^{53}$ 
Still, medical experts believe that any of the three vaccines currently being used in the US continue to show good protection against variants.

To end the confusion, the EMA has required all the vaccine developers to investigate whether their vaccine offers protection against new variants. Experts are afraid that some of these mutants may affect the vaccines' ability to protect against infection and disease to varying degrees. The regulatory body is also collaborating with other authorities to determine possible changes to the composition of Covid vaccine regimes and to establish a global strategy.

\section{Discussion}

The panorama on the available vaccines is very broad and may lead to unclear choices due to the differing characteristics of both vaccines and patients. Many open questions remain concerning the lack of sufficient doses and other priority criteria by different countries. For instance, the efficacy of the vaccines is generating the existence of series A (more effective and more expensive) and series B (less effective and less expensive) vaccines. Other concerns refer to delays in the involvement of family doctors and pharmacies for vaccine distribution.

In any case, vaccination campaigns should be accurately evaluated examining dose units, vaccine administration strategies, alternatives to current vaccines, and the problem of virus mutations leading to variants that may result in the vaccination failure. All these aspects are crucial for managing a successful action plan.

\section{Dose Units}

In terms of doses numbers, the UK Government has sponsored a clinical trial to investigate whether individuals can be given different Covid-19 vaccines for each dose. ${ }^{54}$ This trial is assessing whether patients receiving different vaccines for their first and second doses are well protected. If the study results are promising, the government may need to review the vaccine regimen approach. Two different doses of the same vaccine (first half dose then a full dose for the booster) could also be tested. The use of a 12-week interval between the AstraZeneca vaccine doses has generated controversy given the lack of clinical data to support it. A mixed bag of findings exist: It is certainly true that receiving two standard doses 12 weeks apart provides a higher level of protection $(81.3 \%)$ than receiving the doses at an interval shorter than 6 weeks $(55.1 \%) .{ }^{55}$ For the Moderna vaccine, a single dose has been proposed because it provided the same immunological response as two doses over a short window of time. A big study on hundreds of people, showed that half-doses were non-inferior to full doses, suggesting that the number of individuals immunized in an emergency situation could be doubled providing a great advantage. ${ }^{56}$

In patients who have had a previous Covid-19 infection, the first dose of the vaccine acts as a booster therefore, a second dose might not be needed. ${ }^{57}$

A single dose of Covid-19 mRNA vaccine elicited rapid immune responses in seropositive participants, with post-vaccination antibody titers that were similar to or exceeded the titers found in seronegative participants who received two vaccination doses, according to a study published in the New England Journal of Medicine. ${ }^{58}$

\section{Vaccination Strategy}

Regarding the vaccine campaign strategy, vaccinations by age group remain the simplest, most transparent and fair criterion beginning with the older populations and gradually continuing with the younger ones with the health care staff and the weak people with serious co-morbidities (and possibly other categories of individuals such as the teachers) having the absolute priority. The vaccination strategy attempts to accelerate vaccine administrations, so that as many subjects as possible can be vaccinated quickly to achieve a global immunization (the so-called "herd immunity") in a short time. ${ }^{50}$

\section{Alternative Solutions Beyond Vaccines}

In cases of both vaccine inefficacy or vaccination impossibility due to a previously documented allergy, new treatments to combat the infection could be an alternative. Monoclonal antibodies have been shown to be effective against the SARS-CoV-2 virus and, most importantly, against the virus variants that can be resistant to the immunization induced by the current vaccines. ${ }^{59}$ This therapeutic option can be an alternative strategy to the vaccination campaign to control the pandemic. The Technical Scientific Commission of the AIFA has given the authorization to use monoclonal antibodies in Italy. Two of them have been approved for the treatment of Covid, those produced by Regeneron and by Eli Lilly Pharmaceutical. The CHMP of the EMA is reviewing the available data on the use of the monoclonal antibodies casirivimab, imdevimab, bamlanivimab, and etesevimab for the treatment of patients with Covid-19 who do not require oxygen supplementation, but who are at high risk of progressing 
to severe Covid-19. The FDA issued an emergency use authorization (EUA) for bamlanivimab and etesevimab administered together for adults and pediatric patients. Very recently, the Independent Data Monitoring Committee (IDMC) evaluating the monoclonal antibody VIR-7831 (GSK4182136) developed by Vir Biotechnology and GlaxoSmithKline as monotherapy for early treatment of Covid-19 in adults at high risk of hospitalization, has found profound efficacy against current and worrisome circulating variants of SARSCoV-2, including those from the UK, South Africa, and Brazil. This monoclonal antibody has demonstrated an $85 \%$ reduction in hospitalizations or deaths, based on data from 583 patients enrolled in the study. ${ }^{60}$

\section{Variants}

The presence of variants of SARS-Cov-2 virus and especially the recently detected Delta variant induced a decrease of vaccines efficacy even though Pfizer, Moderna and Janssen kept a good level of protection as reported above. $^{43}$

\section{Problems Related to the mRNA and DNA Vaccines}

It is well known that RNA is highly degradable and may last only up two days in our body. As a result of this, it must be protected in a lipoprotein particle before being injected to the population. Besides, the mRNA vaccines (Pfizer and Moderna) show the inconvenience of storage temperature. Indeed in order to preserve their activity, it is necessary to keep these vaccines at very low temperatures $\left(-70^{\circ} \mathrm{C}\right.$ or $\left.-20^{\circ} \mathrm{C}\right)$. This is a huge drawback for poor countries with a low standard of living.

As for DNA vaccines such as E-Vax, more specific and complex equipment is necessary even if DNA is a stable molecule. Among the technologies available for vaccine development, DNA vaccination is a promising alternative to conventional vaccines because of its ability to elicit both humoral and cellular immune responses. Compared to mRNA vaccines, there are relevant advantages regarding producibility, stability, and mainly the storage that does not require very low temperatures what constitutes a big issue for the transport and conservation in nations at low income. ${ }^{61}$

\section{Conclusion}

In all, despite the giant steps that have been taken, the global vaccination situation remains unclear and presents many underlined uncertainties. The withdrawal of the AstraZeneca vaccine on March 15 of 2021 after it having been under use for quite a long time in the UK and in some European countries, created confusion in the population. In addition, the Janssen vaccine pause by the FDA on April 13, 2021, owing to the presence of six cases of severe blood clots led to delays in the vaccination campaign.

Several vaccines all over the world have been produced or are still in progress. Those currently used in Italy as well in other European countries are basically three: Pfizer/BioNTech, Moderna, and AstraZeneca (back on the market three days after its withdrawal on March 18th 2021). The Sputnik vaccine is presently used in Russia, in one Italian region (San Marino) and in other countries, whereas the Janssen single-dose vaccine (Johnson \& Johnson from the USA) remains under evaluation. Pfizer was the first distributed vaccine in the USA. The vaccination started in Italy on December 27 of 2020 (Vax-day) vaccines by Pfizer followed by those by Moderna and then by AstraZeneca. The first two vaccines are considered the best ones as they take advantage of a new technology based on mRNA molecules for spike protein production that are included into a lipidic particle that does not get mixed with other mRNAs. These mRNA vaccines are simpler than those constituted by proteins, which are more difficult to manufacture and require more time for FDA approval due to the many steps that must be checked. The manufacturing process for any given protein is complex, whereas that for RNAs is always the same. The successful Pfizer and Moderna vaccines got their approval very fast within 10 months.

A look to the future focuses on Pfizer, which has begun to evaluate both the safety and immunogenicity of a third dose of its Covid-19 vaccine BNT162b2 as a booster for immunity against Covid-19 caused by emerging virus variants ${ }^{62}$ and on the in vitro studies for the clinical candidate PF-07321332, an oral investigational vaccine acting as a potent protease inhibitor with strong anti-viral activity. ${ }^{63}$

The hope for better vaccination programs to allow for a return to normal everyday life, lies in the next-generation Covid-19 vaccines. For a vaccine to be considered "nextgeneration", it must take a different approach than just using the SARS-CoV-2 virus's mRNA to tell the body's cells to produce the virus's distinctive spike protein. Nextgeneration vaccines will be able to protect against viruses with spike mutations with the generation of broader and more potent T-cell responses than the available vaccines. 
The viral structural nucleocapsid $(\mathrm{N})$ is another protein to be considered because it may increase the cellular immune response. $^{64}$

We hope to be able to reach a mild endemic status within six months to a year, in which Covid-19 is considered a simple cold or a flu; this will be possible by maintaining social distancing and achieving a high vaccination rate. $^{65}$

\section{Acknowledgments}

I wish to thank Dr. Roberta Pisano for her valuable support in the bibliographic research and Dr Dania Al Ismail for her valid help in preparing the figures of the manuscript.

\section{Disclosure}

The authors declare no conflict of interest.

\section{References}

1. Kumar S, Nyodu R, Maurya VK, Saxena SK.Morphology, genome organization, replication, and pathogenesis of severe acute respiratory syndrome coronavirus 2 (SARS-CoV-2). coronavirus disease 2019 (COVID-19). Coronavirus Dis. 2020:23-31. doi:10.1007/978-981-154814-7_3

2. Chen Y, Liu Q, Guo D. Emerging coronaviruses: genome structure, replication, and pathogenesis. J Med Virol. 2020;92(4):418-423. doi: $10.1002 /$ jmv. 25681

3. Ho D, Tsuji M. Infectious diseases: breakthroughs in developing vaccines, immune protective monitoring and measuring toxicity with functional proteomics. Isoplexis e-Book. 2020;3. Available from: https://isoplexis.com/literature/infectious-disease-break throughs-in-developing-vaccines-protective-immune-monitoring-mea suring-toxicity/.

4. Ball P. The lightning-fast quest for COVID vaccines - and what it means for other disease. Nature. 2021;508:16-18. doi:10.1038/ d41586-020-03626-1

5. Ravichandran S, Coyle E, Klenow L, Tang J, Grubbs G, Liu S. Antibody signature induced by SARS-CoV-2 spike protein immunogens in rabbits. Sci Transl Med. 2020;12(550):eabc3539. doi:10.1126/ scitranslmed.abc3539

6. Tsuji M, Akkina R. Development of humanized mouse models for infectious diseases and cancer. Front Immunol. 2020. 10:3051. doi:10.3389/fimmu.2019.03051

7. Le TT, Andreadakis Z, Kumar A, et al. The COVID-19 vaccine development landscape. Nat Rev Drug Discovery. 2020;19:305-306. doi:10.1038/d41573-020-00151-8

8. Pardi N, Hogan MJ, Porter FW, Weissman D. mRNA vaccines a new era in vaccinology. Nat Rev Drug Discovery. 2018;17:261-279. doi:10.1038/nrd.2017.243

9. Zhou X, Jiang X, Qu M, et al. Engineering antiviral vaccines ACS nano. ACS nano. 2020;1(14):12370-12389.

10. How mRNA vaccine works; 2021. Available from: https://youtube. com/watch?v=0vvygJ-vwo. Accessed July 29, 2021.

11. Cox RJ, Brokstad KA. Not just antibodies: $\mathrm{b}$ cells and T cells mediate immunity to COVID-19. Nat Rev Immunol. 2020;20(10):581-582. doi:10.1038/s41577-020-00436-4

12. Ninja Nerd lectures; 2020. Covid-19 vaccines: Moderna and PfizerBioNTech Available from: http://wwwyoutube.com/watch? $\mathrm{v}=$ 35ldbICU4o Accessed July 29, 2021.
13. Dan JM, Mateus J, Yu K, Hastie K, Faliti CM, Ramirez S. Immunological memory to SARS-CoV-2 assessed for greater than six months after infection. bioRxiv. 2021;371:6529. doi:10.1101/ 2020.11.15.383323;

14. Zhenyu H, Ren L, Yang J, et al. Seroprevalence and humoral immune durability of anti-SARS-CoV-2 antibodies in Wuhan, China: a longitudinal, population-level, cross-sectional study. Lancet. 2021;397(10279):1075-1084. doi:10.1016/S0140-6736(21)00238-5

15. McNeill MM, De Stefano F. Vaccine-associated hypersensitivity. $J$ Allergy Clin Immunol. 2018;141(2):463-472. doi:10.1016/j. jaci.2017.12.971

16. Shimabukuro T, Nair N. Allergic reactions including anaphylaxis after receipt of the first dose of pfizer-BioNTech COVID-19 vaccine. JAMA. 2021;325(8):780-781. doi:10.1001/jama.2021.0600

17. Walsh E, Frenck RW, Falsey AR, et al. Safety and Immunogenicity of two RNA-based covid-19 vaccine candidates. $N$ Engl $J$ Med. 2020;383:2439-2450. doi:10.1056/NEJMoa2027906

18. Vaccine Pfizer data sheet; 2021.Fact sheet for healthcare providers administreting vaccines (vaccination providers) emergency use authorization (EUA) of Pfizer/BioNTech Covid 19 vaccine to prevent Coronavirus disease 2019 (Covid-19). Available from: https://www. fda.gov/media/144413/download. Accessed July 29, 2021.

19. Vaccine Moderna data sheet; 2020. Fact sheet for healthcare prividers administreting (EUA) of vaccines (vaccination providers) emergency use authorization of Moderna Covid-19 vaccine to prevent Coronavirus disease 2019 (Covid-19). Available from: https://www. fda.gov/media/144637/download. Accessed July 29, 2021.

20. Sette A, Crotty S.. Adaptive immunity to SARS-CoV-2 and COVID-19. Cell. 2021;184(4):861-880. doi:10.1016/j. cell.2021.01.007

21. Pai M, Schull M, Razak F, et al. Vaccine - induced prothrombotic immune thrombocytopenia (VIPIT) following AstraZeneca COVID19 vaccination. Sci Briefs. 2020. http://covid19-sciencetable.ca/ science-briefs.

22. Greinacher A, Thiele $\mathrm{T}$, Warkentin $\mathrm{T}$, Weisser $\mathrm{K}$, Kyrle $\mathrm{P}$, Eichinger S. A prothrombotic thrombocytopenic disorder resembling heparin-induced thrombocytopenia following coronavirus-19 vaccination research square. Preprint April 7, 2021

23. Vilches TN, Zhang K, Van ER, Langley JM, Moghadas SM. Projecting the impact of a two- dose COVID-19 vaccination campaign in Ontario, Canada. Vaccine. 2021;39(17):2360-2365. doi:10.1016/j.vaccine.2021.03.058

24. Emary K, Golubchik T, Aley P, et al. Efficacy of ChAdOx1 nCoV-19 (AZD1222) vaccine against SARS-CoV-2 variant of concern 202012/ 01 (B.1.1.7): an exploratory analysis of a randomised controlled trial. Lancet. 2021;397(10282):1351-1362. doi:10.1016/S0140-6736(21) 00628-0

25. The Oxford/AstraZeneca COVID-19 vaccine: what you need to know; Updated March 17, 2021.from World Health Organization (WHO) Available from: https://www.who.int/news-room/feature-stories/detail/theoxford-astrazeneca-covid-19-vaccine-what-you-need-to-know?gclid= Cj0KCQjw6s2IBhCnARIsAP8RfAj7JJxAKzNgcMEEpd2jng5BmdtlwtVYJaRUbWD4C2IG5rxbXlu11UaAlZFE. Accessed July 29, 2021.

26. Suschak J, Williams JA, Schmaljohn CS. Advancements in DNA vaccine vectors, non-mechanical delivery methods, and molecular adjuvants to increase immunogenicity. Hum Vaccines Immunother. 2017;13:2837-2848. doi:10.1080/21645515.2017.1330236

27. Seheult R. (UC Riverside School of Medicine, University of California). Coronavirus update 121;Johnson and Johnson vaccine vs Pfizer and Moderna 2021. Available from: https://www.youtube. com/watch?v=13qT7wLxkvU\&t=602s. Accessed July 29, 2021.

28. Grifoni A, Weiskopf D, Ramirez S, et al. Targets of T cell responses to SARS-CoV-2 coronavirus in humans with COVID-19 disease and unexposed individuals. Cell. 2020;181(7):1489-1501. 
29. National Institute of Allergy and Infectious disease (NIAID) and Pharmaceutical Janssen Companies from the U.S. Department of Health and Human Services':2021, February 29: Janssen investigational COVID-19 vaccine: interim analysis of phase 3 clinical data released. Available from: https://www.nih.gov/news-events/news-releases/jans sen-investigational-covid-19-vaccine-interim-analysis-phase-3-clinicaldata-released. Accessed July 29, 2021.

30. Vaccine Janssen data sheet)2021. John Galloway (King's College London) Available from: https://www.janssenlabels.com/emergencyuse-authorization/Janssen+COVID-19+Vaccine-HCP-fact-sheet.pdf. Accessed July 29, 2021.

31. Jones I, Roy P, Sputnik V. COVID-19 vaccine candidate appears safe and effective. Lancet. 2021;397(10275):642-643. doi:10.1016/ S0140-6736(21)00191-4

32. Logunov D, Dolzhikova I, ShcheblyaKov D, et al. Safety and efficacy of an rAd26 and rAd5 vector-based heterologos prime-boost COVID-19 vaccine: interim analysis of a randomised controlled phase 3 trial in Russia. Lancet. 2021;397(10275):671-681. doi:10.1016/S0140-6736(21)00234-8

33. Vaccine Novavax; 2021. Available from: https://ir.novavax.com/ news-releases/news-release-details/novavax-covid-19-vaccine-demon strates-893-efficacy-uk-phase-3. Accessed July 29, 2021.

34. Heath PT, Galiza EP, Baxter DN, Boffito M, Browne D, Burns F. Safety and efficacy of NVX-CoV2373 Covid-19 vaccine. New Engl J Med. 2021. doi:10.1056/NEJMoa2107659

35. Vaccine Reithera; March 18, 2021. Folgori A from INMI Spallanzani, Rome (Italy). Available from: https://reithera.com/2021/03/18/vac cino-anti-covid-19-al-via-la-seconda-fase-di-sperimentazione-direithera/?lang=it. Accessed July 29, 2021.

36. Vaccine Sinovac. 2021. from BBC news Avaialble from: https:// www.bbc.com/news/world-asia-china-55212787. Accessed July 29, 2021.

37. Jara A, Undurraga EA, González C, et al. Effectiveness of an inactivated SARS-CoV-2 vaccine in chile. New Engl J Med. 2021. doi:10.1056/NEJMoa2107715

38. Buonaguro FM, Ascierto P, Morse G, et al. Covid-19: time for a paradigm change. Rev Med Virol. 2020;30(5):e2134. doi:10.1002/ rmv. 2134

39. E-Vax Italian vaccine. Available from: https://www.takisbiotech.it/ index.php/news. Accessed July 29, 2021.

40. Wodi AP, Ault K, Hunter P, McNally V, Szilagyi PG, Henry Bernstein $\mathrm{H}$. Advisory committee on immunization practices recommended immunization schedule for children and adolescents aged 18 years or younger - United States, 2021.-. MMWR Morb Mortal Wkly Rep. 2021;70(6):189-192. doi:10.15585/mmwr.mm7006a1

41. Covid EU approves : Pfizer-BioNTech jab for 12-15 years old fromBBC news published May 28. 2021. Available from: https:// bbc.com/news/world-europe-57287755.

42. Kim HW, Jenista ER, Wendell DC, et al. Patients with acute myocarditis following mRNA COVID-19 vaccination. JAMA Cardiol. 2021. doi:10.1001/jamacardio.2021.2828

43. Dagan N, Barda N, Kepten E, Miron O, Perchik S. BNT162b2 mRNA covid-19 vaccine in a nationwide mass vaccination setting. $N$ England $J \quad M \quad E d$. 2021;384:1412-1423. doi:10.1056/ NEJMoa2101765ex51

44. European Centre for Disease Prevention and Control. Risk related to the spread of new SARS-CoV-2 variants of concern in the EU/EEA first update. Stockholm: ECDC; 2021. Available from: https://www. ecdc.europa.eu/en/publications-data/covid-19-risk-assessmentspread-new-variants-concern-eueea-first-update. Accessed July 29, 2021

45. Rambaut A, Loman N, Pybus O, et al. Preliminary genomic characterization of an emergent SARS-CoV-2 lineage in the UK defined by a novel set of spike mutations. 12, Report Superior sanity Institute (ISS). Bruno Kessler Foundation and Health Ministry; 2021.
46. Xie X, Zou J, FontesGarfias C, Hongjie X, Kena AS, Cutler M et al. Neutralization of N501Y mutant SARS-CoV-2 by BNT162b2 vaccine-elicited serra. BioRxiv. 2021. doi:10.1101/2021.01.07.425740

47. Liu Y, Liu J, Xia H, Xianwen Z, Fontes-Garfias C. Neutralizing activity of BNT162b2-elicted serum. $N$ Engl $J$ Med. 2021;384:1466-1468. doi:10.1056/NEJMc2102017

48. NGS-SA Group Wits-VIDA COVID Group. Efficacy of the ChAdOx1 nCoV-19 vaccine against the B.1.351 variant. $N$ Engl J Med. 2021. doi:10.1056/NEJMoa2102214

49. Rubin R. COVID-19 vaccines vs variants-determining how much immunity is enough. JAMA. 2021;325(13):1241-1243. doi:10.1001/ jama.2021.3370

50. Lipsitch M, Grad Y H, Sette A, Crotty S. Cross-reactivity memory $\mathrm{T}$ cell and herd immunity to SARS-CoV-2. Nat Rev Immunol. 2020;20:709-713. doi:10.1038/s41577-020-00460-4

51. Jalkanen P, Kolehmainen P, Häkkinen HK, et al. COVID-19 mRNA vaccine induced antibody responses against three SARS-CoV-2 variants. Nat Commun. 2021;12:1. doi:10.1038/s41467-021-24285-4

52. Anthes E. The delta variant: what scientists know. in the New York Times; 2021.

53. Venkata-Viswanadh E, Pinsky BA, Suthar M, et al. Infection and vaccine-induced neutralizing-antibody responses to the SARS-CoV-2 B.1.617 variants. $N$ Engl J Med. 2021. doi:10.1056/NEJMc2107799

54. EPR: UK launches clinical trial to study alternating COVID-19 vaccines for different doses; February 4, 2021. Rees V. from National Institute for Health Research (NIHR) in the UK Available from: https://www.europeanpharmaceuticalreview.com/news/141736/ uk-launches-trial-to-study-alternating-covid-19-vaccines-for-differ ent-doses/. Accessed July 29, 2021.

55. Oxford COVID Vaccine Trial Group. Single-dose administration and the influence of the timing of the booster dose on immunogenicity and efficacy of ChAdOx1 nCoV-19 (AZD1222) vaccine: a pooled analysis of four randomised trials. Lancet. 2021;397(10277):881-891.

56. Berkeley L. One dose of Pfizer or Moderna vaccines was $80 \%$ effective in preventing Covid in CDC study of health workers. Health Sci. March 29, 2021. Available from: https://www.cnbc.com/ 2021/03/29/cdc-study-shows-single-dose-of-pfizer-or-modernacovid-vaccines-was-80percent-effective.html.

57. Manisty C, Otter Ashley D, Triebel T, et al. Antibody response to first BNT162b2 dose in previously SARS-CoV-2-infected individuals. Lancet. 2021;397(10279):1057-1058. doi:10.1016/S0140-6736(21)00501-8

58. Krammer F, Srivastava K, Alshammary H, et al. Antibody responses in seropositive person after a single dose of SARS-CoV-2 mRNA vaccines. N Engl J Med. 2021;384:1372-1374. doi:10.1056/NEJMc2101667

59. Salim S, Abdool K, De Oliveira T. New SARS-CoV-2 variants-clinical, public health, and vaccine implications. $N$ Engl $J$ Med. 2021. doi:10.1056/NEJMc2100362

60. GlaxoSmithKline clinical trial COMET-ICE (Covid-19 monoclonal antibody efficacy trial - intent to care early) study for the evaluation of VIR-7831; 2020.Landazabal F. from GSK S.p.A Available from: http://www.quotidianosanita.it/scienza-e-farmaci/articolo.php?arti colo_id=88609. Accessed July 29, 2021.

61. Silveira MM, Moreira GMSG, Mendonça M. DNA vaccines against COVID-19: perspectives and challenges. Life Sci. 2021;267:118919. doi:10.1016/j.1fs.2020.118919

62. Pfizer, BioNTech study 3rd booster of vaccine to protect against variants [dissertation] By The Science Advisory Board staff writers, February 25,2021. Available from: https://www.scienceboard.net/ index.aspx?sec $=$ sup\&sub $=$ can\&pag $=$ dis $\& I t e m I D=2222 \mathrm{https}: / / \mathrm{www}$. scienceboard.net/index.aspx? sec $=$ sup\&sub $=$ can\&pag $=$ dis\&ItemID $=$ 2222 . Accessed July 29, 2021.

63. Pfizer initiates phase 1 study of novel oral antiviral therapeutic agent against SARS-CoV-2; March 23, 2021. Elsele P. from Pfzer S p A Available from: https://www.pfizer.com/news/press-release/pressrelease-detail/pfizer-initiates-phase-1-study-novel-oral-antiviral. Accessed July 29, 2021. 
64. Blakney A, McKay P. Next generation COVID-19 vaccines: here come the proteins. Lancet. 2021;39:643-644. doi:10.1016/S01406736(21)00258-0
65. Lavine S, Bjornstad O. Immunological characteristics govern the transition of COVID-19 endemicity. Science. 2021;371 (6530):741-745. doi:10.1126/science.abe6522

\section{Publish your work in this journal}

Infection and Drug Resistance is an international, peer-reviewed openaccess journal that focuses on the optimal treatment of infection (bacterial, fungal and viral) and the development and institution of preventive strategies to minimize the development and spread of resistance. The journal is specifically concerned with the epidemiology of

Submit your manuscript here: https://www.dovepress.com/infection-and-drug-resistance-journal antibiotic resistance and the mechanisms of resistance development and diffusion in both hospitals and the community. The manuscript management system is completely online and includes a very quick and fair peerreview system, which is all easy to use. Visit http://www.dovepress.com/ testimonials.php to read real quotes from published authors. 